\title{
A Cost-Effective Rabbit Embolic Stroke Bioassay: Insight into the Development of Acute Ischemic Stroke Therapy
}

\author{
Paul A. Lapchak
}

Received: 4 January 2015 / Accepted: 6 January 2015 /Published online: 1 February 2015

(C) Springer Science+Business Media New York 2015

\section{Preface: 30 Years a Model}

This article was written to acknowledge the scientific achievement of Dr. Justin A. Zivin, the originator of the rabbit embolic stroke model and investigator responsible for the "translational stroke research" that led to the NINDS rt-PA trial and eventual approval of tissue plasminogen activator (tPA) for the treatment of acute ischemic stroke 20 years ago. In 1984-1985, the term "translational stroke research" did not exist, nor did this journal bearing the name Translational Stroke Research. Nevertheless, over the years, the rabbit embolic stroke model has been integral in the development and testing of novel therapies, and the model remains important for translational stroke therapy development. Translational Stroke Research has become an important means of disseminating advances in basic and translational stroke research and will be integral in future stroke therapy discovery.

\section{tPA, a Cost-Effective Treatment}

tPA has been described as a cost-effective treatment for stroke [1] when administered 3 to $4.5 \mathrm{~h}$ after a stroke. The specific conclusion is derived using a disease-based decision analytic model, which included probabilistic sensitivity analyses, indicating that "improvement in long-term patient outcomes in most patient subgroups

\section{P. A. Lapchak ( $\triangle)$}

Departments of Neurology and Neurosurgery, Cedars-Sinai Medical Center, Advanced Health Sciences Pavilion Suite 8305, 127 S. San

Vicente Blvd., Los Angeles, CA 90048, USA

e-mail: Paul.Lapchak@cshs.org (except for diabetes and atrial fibrillation) and is a good economic value versus no treatment" [1]. This has been confirmed in two recent reports using extensive patient databases $[2,3]$.

In 1996, the Food and Drug Administration (FDA) approved the thrombolytic tPA for the treatment of acute ischemic stroke resulting from blockage of a vessel due to an embolus or blood clot. tPA, a thrombolytic that promotes clot lysis, is also known as a clot buster that increases blood flow to the formerly clot-affected core and possibly salvageable penumbra [4-13]; this results in clinical and/or behavioral improvement on the National Institutes of Health Stroke Scale (NIHSS) and modified Rankin Scale (mRS). Almost 20 years have passed without the approval of another stroke treatment despite the tremendous financial investments and achievements of many investigators worldwide!

\section{A Rigorous Model and Bioassay for Therapy Testing and Development}

The approval of tPA was based upon a randomized and blinded clinical trial comparing tPA to tPA-placebo; the trial was initiated based upon preclinical data by Zivin and colleagues, which was published 30 years ago in a landmark science paper [14] and eventually detailed in a volume dedicated to the history of tPA [15] as well as other comprehensive books on thrombolytics and translational stroke research [16-19]. In retrospect, the authors simply showed that tPA could effectively improve behavioral function when tested in a noninvasive rabbit embolic stroke model, now known as the rabbit small 
clot embolic stroke model (RSCEM) [reviewed in [20, 21]].

"Facts do not cease to exist because they are ignored." —Aldous Huxley (1894-1963)

- A model is classically defined as a system used as an example to follow or imitate; thus, the RSCEM, which is an embolism model, imitates aspects or features of human acute ischemic stroke.

The therapeutic effect of tPA is the same in man and rabbits, increased reperfusion with substantial clinical improvement with the known side effect of increased intracerebral hemorrhage (ICH).

This article will briefly detail a few salient aspects of the RSCEM, which make it extremely useful for drug and device efficacy and safety studies. The RSCEM can be used as a primary species model to support an Investigational New Drug (IND)/Investigational Device Exemption (IDE)/New Drug Application (NDA), or it can be used in conjunction with one of many available invasive rodent models [22] to fulfill Stroke Therapy Academic Industry Roundtable (STAIR) criteria [23]; studies using the rigorous RSCEM can also incorporate RIGOR guidelines [24, 25].

\section{The Benefits of Therapy Testing in the RSCEM Bioassay}

1. No anesthetic interference: In the current version of the RSCEM [20], rabbits are allowed to recover from the effects of inhaled anesthesia (i.e., either halothane or isoflurane) for at least $2 \mathrm{~h}$ before embolization. The absence of any form of anesthesia during the embolization procedure is beneficial when studying "neuroprotection," since anesthetics have been shown to be neuroprotective or neurotoxic and can interfere with the ischemic cascade [21, 26-33]. The possibility of deleterious interactions can confound the interpretation of valuable scientific data due to drug-drug interactions, efficacy masking or potentiation, and anesthetic-induced regulation of multiple components of the ischemic cascade [34, 35]. This may limit the translation of animal model data to the clinic as described by O'Collins et al. [22]. Moreover, in the RSCEM, analgesics are also not administered because of the potential to interfere with the ischemic stroke cascade [21].
2. Heterogeneous population: In the RSCEM, a solution of non-autologous small-sized blood clots is prepared prior to embolization $[7,21,36]$. Because the response to embolization is heterogeneous, this results in a behaviorally heterogeneous population much like that enrolled in every stroke clinical trial. A sophisticated statistical method was devised by Zivin and Waud [37] to take advantage of the heterogeneous population being studied. The statistical method is also used in two innovative ischemia bioassay models $[38,39]$.

- Should a heterogeneous stroke model be used for therapy development? Yes [see [20, 21, 40, 41]]. Clinical trial enrollment data derived from randomized and blinded clinical trial such as the original NINDS rt-PA clinical trial report [42] shows that the patient population included in the placebo control group had NIHSS scores of 1-32, and the active drug group had a range from 1 to 37 [42]. This clinical trial patient population encompassed a wide range of NIHSS scores, indicative of widespread heterogeneity within each experimental study group. More recent trials that have attempted to limit patient population enrollment to a specific short range have been quite unsuccessful [43-49].

3. Clinically relevant end point: The primary end point used when assessing treatment efficacy in the RSCEM is behavioral functional, which is based upon motor function components of the NIHSS [50]. The use of clinical rating scores is a desirable primary end point to use when developing a novel therapeutic [20,21]]. Clinical scores in combination with quantal analysis is a sophisticated statistical analysis method to determine how a large population of stroke "patients" such as a group of 15-20 rabbits will respond to a treatment $[7,21,36]$. To evaluate the quantitative relationship between clot burden in brain and clinical scores, logistic sigmoidal quantal analysis curves are constructed as originally described by Waud [51] and thereafter [7, 21, 36]. One important aspect of the model is the use of a wide range of clot doses injected into the brain via an indwelling carotid catheter, which allows the investigator to produce a spectrum of behaviorally normal to abnormal animals, which does include death on the continuum of embolization-induced effects $[20,21]$. Unlike most rodent stroke models, where animals are routinely excluded to refine 
group data, when using the RSCEM, rabbits are seldom excluded from a study. Only under specific circumstances that warrant exclusion such as technical problems during embolization or the need for early euthanasia prior to complete treatment administration are animals excluded from a study.

4. Positive-controlled studies: For drug and device development purposes, it is essential to utilize a model where a current FDA-approved therapy can be used as a positive control to ensure the validity of data. For ischemic stroke, this is limited to tPA worldwide [52] and Radicut (edaravone) in Japan [53]. Studies done without the use of a positive control, preferably a drug used clinically to treat the disease, have limited value during the drug development process.

Using the RSCEM, an example of a sigmoidal dose-response curve is presented in Fig. 1. After behavior is measured in a blinded manner, clot burden is measured in order to construct the quantal curve. In the Figure, tPA used at a standard dose previously described to be effective in rabbits [7], reduced embolization-induced behavioral deficits, which is represented by a statistically significant increase in $P_{50}$ value $(p<0.05$; unpaired $t$ test, Graph Pad Inc.). For complete details of the bioassay method, please refer to references $[20,21]$.

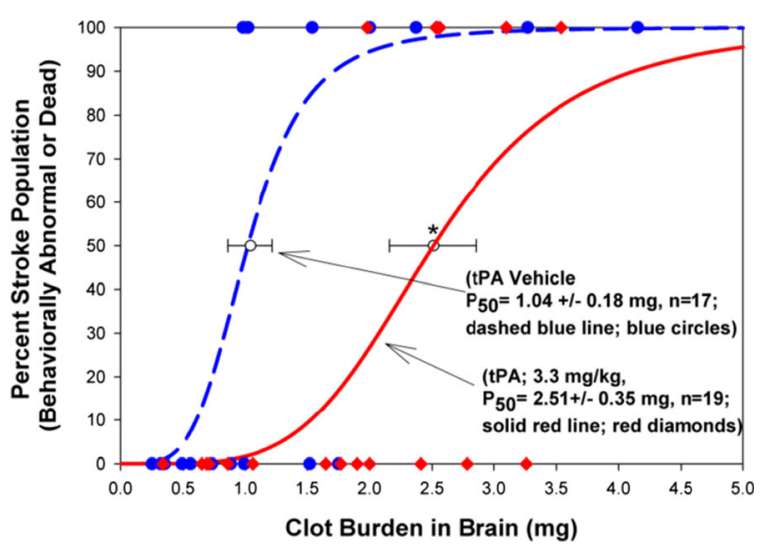

Fig. 1 Effect of tPA on behavioral outcome using the RSCEM. For the superimposed graphs, behaviorally normal animals are plotted on the $y$-axis at 0 , and abnormal animals are plotted at 100. The figure shows that there is positive correlation between the raw data and the statistically fit sigmoidal quantal curves. Quantal analysis curves are provided for both the tPA vehicletreated group and the tPA $(3.3 \mathrm{mg} / \mathrm{kg} ; 20 \%$ bolus, $80 \%$ infused intravenous)-treated group. tPA significantly improves behavior, which is reflected by an increased $P_{50} \quad(p<0.05)$ compared to tPA vehicle
5. Safety and combination drug testing: The RSCEM also has the enormous advantage of being a model where drugs and devices can be studied in combination with TPA as a positive control. The therapy can be administered coincidently with tPA or following tPA administration to simulate current clinical trial design. The combination studies will allow the investigator to determine if the drug/device of choice inhibits or potentiates tPA efficacy or affects the safety profile of tPA, since tPA can cause ICH in patients and embolized rabbits [54-62]. The consequence of the new therapy on ICH incidence and mortality can be measured $[63,64]$. The safety measure data is valuable during the combination therapy development process.

6. Cost-effective: The RSCEM model is highly costeffective for therapy development. If one incorporates the recommended tPA positive control into the study design, then the investigator will have determined if the novel therapy is equivalent to tPA's efficacy and therapeutic window $(1 \mathrm{~h}$ in rabbits, equivalent to approximately $3 \mathrm{~h}$ in humans) [20,21]. Thus, the data can easily be interpreted and advanced to a clinical trial for a small investment in RSCEM translational research studies compared to the actual enormous cost of a clinical trial.

The recent report by Levine and Hill documents that the NEST-2 laser trial had a cost of approximately $\$ 50$ million, and the subsequent NEST-3 trial was ended due to futility after allocating more than $\$ 60$ million to the trial [65]. It should be noted that the cited estimates are on the low end of actual costs to conduct a clinical trial for a small molecule or biologic through to completion.

7. STAIR criteria and RIGOR guidelines: In the recent issues of Translational Stroke Research, investigators have published basic research showing that there are many "new" targets, methods, and molecules that can be mined to treat stroke. STAIR criteria recommend testing the therapies in multiple species to ensure efficacy of the treatment in different models and in different laboratories. Moreover, this will improve translation into the clinic in stroke patients. The reader is referred to original articles for details regarding STAIR criteria [23] and RIGOR guidelines $[24,25,66]$.

Preclinical testing in vitro and in rodents has provided the impetus for further development of neuroprotectants [67] to attenuate stroke-induced "behavioral deficits," using remote preconditioning [68-70] or even provide a basis for regeneration of critical pathways involved in clinical deficits [71]. There are many models available for therapy testing 
including models that have been refined to allow for shortand long-term behavioral measures [72-75].

\section{Conclusion}

The RSCEM is a useful and cost-effective translational animal model that can be utilized for drug and device development for both monotherapy and combination therapy.

- Studies are conducted in the absence of interfering anesthetics and analgesics.

- The model incorporates a heterogeneous stroke population.

- The model utilizes a sophisticated statistical approach to determine the clinical response of a heterogeneous population.

- The model is clot based; studies can be designed to include a positive-control group (i.e., tPA) and combinationtreated groups (i.e., tPA plus drug/device) to expedite drug and device development toward IND/IDE/NDA.

- The model is cost-effective.

Acknowledgments The writing of this article was supported by donations to PAL to fund stroke research and a U01 Translational research grant NS060685 to PAL.

Conflict of Interest The author is the Editor-in-Chief of the Journal of Neurology and Neurophysiology and the Associate Editor for Translational Stroke Research.

\section{References}

1. Boudreau DM, Guzauskas G, Villa KF, Fagan SC, Veenstra DL. A model of cost-effectiveness of tissue plasminogen activator in patient subgroups 3 to 4.5 hours after onset of acute ischemic stroke. Ann Emerg Med. 2013;61(1):46-55.

2. Pan Y, Chen Q, Zhao X, Liao X, Wang C, Du W, et al. Costeffectiveness of thrombolysis within 4.5 hours of acute ischemic stroke in China. PLoS ONE. 2014;9(10):e110525.

3. Boudreau DM, Guzauskas GF, Chen E, Lalla D, Tayama D, Fagan $\mathrm{SC}$, et al. Cost-effectiveness of recombinant tissue-type plasminogen activator within 3 hours of acute ischemic stroke: current evidence. Stroke. 2014;45(10):3032-9.

4. del Zoppo G. Thrombolytic therapy in cerebrovascular disease. Curr Concepts Cereb Dis. 1988;23:7.

5. Hacke W, Kaste M, Fieschi C, von Kummer R, Davalos A, Meier D, et al. Randomised double-blind placebo-controlled trial of thrombolytic therapy with intravenous alteplase in acute ischaemic stroke (ECASS II). Second European-Australasian Acute Stroke Study Investigators. Lancet. 1998;352(9136):1245-51.

6. Lapchak PA. Development of thrombolytic therapy for stroke: a perspective. Expert Opin Investig Drugs. 2002;11(11):1623-32.
7. Lapchak PA, Araujo DM, Zivin JA. Comparison of Tenecteplase with Alteplase on clinical rating scores following small clot embolic strokes in rabbits. Exp Neurol. 2004;185(1):154-9.

8. Lyden PD. Should all stroke patients receive tissue plasminogen activator therapy, despite mild or improving symptoms? Nat Clin Pract Cardiovasc Med. 2006;3(4):184-5.

9. Lyden PD, Lees KR, Davis SM. Alteplase for acute stroke revisited: the first 10 years. Lancet Neurol. 2006;5(9):722-4.

10. Lyden PD, Zivin JA, Clark WA, Madden K, Sasse KC, Mazzarella VA, et al. Tissue plasminogen activator-mediated thrombolysis of cerebral emboli and its effect on hemorrhagic infarction in rabbits. Neurology. 1989;39:703.

11. Hacke W, Donnan G, Fieschi C, Kaste M, von Kummer R, Broderick JP, et al. Association of outcome with early stroke treatment: pooled analysis of ATLANTIS, ECASS, and NINDS rt-PA stroke trials. Lancet. 2004;363(9411):768-74.

12. Hacke W, editor Thrombolysis, Thrombectomy and Acute Stroke Therapy Conference. Thrombolysis, Thrombectomy and Acute Stroke Therapy Conference; 2014; Heidelberg - Mannheim.

13. Lyden P, Lapchak P. Sisyphus and translational stroke research. Sci Transl Med. 2012;4(156):156ps20.

14. Zivin JA, Fisher M, DeGirolami U, Hemenway CC, Stashak JA. Tissue plasminogen activator reduces neurological damage after cerebral embolism. Science. 1985;230(4731):1289.

15. Zivin JA, Simmons J. tPA for stroke : the story of a controversial drug. New York: Oxford University Press; 2011. xiv, 191 p. p.

16. Lapchak PA, Zhang JH. Translational stroke research : from target selection to clinical trials. New York: Springer; 2012. xxiv, 923 p. p.

17. Lyden PD. Thrombolytic therapy for acute stroke. 2nd ed. Totowa, N.J: Humana Press; 2005. xvii, 370 p. p.

18. Lyden PD. Thrombolytic therapy for stroke. Totowa, N.J: Humana Press; 2001. xiv, 410 p. p.

19. Lyden PD. Thrombolytic therapy for acute stroke. New York: Springer; 2014. pages $\mathrm{cm} \mathrm{p}$.

20. Lapchak PA. Translational stroke research using a rabbit embolic stroke model: a correlative analysis hypothesis for novel therapy development. Transl Stroke Res. 2010;1(2):96-107.

21. Lapchak PA. A clinically relevant rabbit embolic stroke model for acute ischemic stroke therapy development: mechanisms \& targets. In: Lapchak PA, Zhang JH, editors. Translational Stroke Research: From Target Selection to Clinical Trials. USA: Springer; 2012. p. 541-84.

22. O'Collins VE, Macleod MR, Donnan GA, Horky LL, van der Worp BH, Howells DW. 1,026 experimental treatments in acute stroke. Ann Neurol. 2006;59(3):467-77.

23. Recommendations for standards regarding preclinical neuroprotective and restorative drug development. Stroke. 1999;30(12):2752-8.

24. Landis SC, Amara SG, Asadullah K, Austin CP, Blumenstein R, Bradley $\mathrm{EW}$, et al. A call for transparent reporting to optimize the predictive value of preclinical research. Nature. 2012;490(7419):187-91.

25. Lapchak PA. Recommendations and practices to optimize stroke therapy: developing effective translational research programs. Stroke. 2013;44(3):841-3.

26. Kawaguchi M, Furuya H, Patel PM. Neuroprotective effects of anesthetic agents. J Anesth. 2005;19(2):150-6.

27. Sanders RD, Ma D, Maze M. Anaesthesia induced neuroprotection. Best Pract Res Clin Anaesthesiol. 2005;19(3):461-74.

28. Head BP, Patel P. Anesthetics and brain protection. Curr Opin Anaesthesiol. 2007;20(5):395-9.

29. Schifilliti D, Grasso G, Conti A, Fodale V. Anaesthetic-related neuroprotection: intravenous or inhalational agents? CNS Drugs. 2010;24(11):893-907.

30. Wei H, Inan S. Dual effects of neuroprotection and neurotoxicity by general anesthetics: role of intracellular calcium homeostasis. Prog Neuropsychopharmacol Biol Psychiatry. 2013;47:156-61.

31. Combes RD. A critical review of anaesthetised animal models and alternatives for military research, testing and training, with a focus on 
blast damage, haemorrhage and resuscitation. Altern Lab Anim : ATLA. 2013;41(5):385-415.

32. Burchell SR, Dixon BJ, Tang J, Zhang JH. Isoflurane provides neuroprotection in neonatal hypoxic ischemic brain injury. J Investig Med. 2013;61(7):1078-83.

33. Karmarkar SW, Bottum KM, Tischkau SA. Considerations for the use of anesthetics in neurotoxicity studies. Comp Med. 2010;60(4):256-62.

34. Dirnagl U, Iadecola C, Moskowitz MA. Pathobiology of ischaemic stroke: an integrated view. Trends Neurosci. 1999;22(9):391-7.

35. Moskowitz MA, Lo EH, Iadecola C. The science of stroke: mechanisms in search of treatments. Neuron. 2010;67(2):181-98.

36. Lapchak PA, Wei J, Zivin JA. Transcranial infrared laser therapy improves clinical rating scores after embolic strokes in rabbits. Stroke. 2004;35(8):1985-8.

37. Zivin JA, Waud DR. Quantal bioassay and stroke. Stroke. 1992;23(5):767-73.

38. Lyden P, Pereira B, Chen B, Zhao L, Lamb J, Lei IF, et al. Direct thrombin inhibitor argatroban reduces stroke damage in 2 different models. Stroke. 2014;45(3):896-9.

39. Lapchak PA, Chapman DF, Nunez SY, Zivin JA. Dehydroepiandro sterone sulfate is neuroprotective in a reversible spinal cord ischemia model: possible involvement of GABA (A) receptors. Stroke. 2000;31: 1953-6.

40. Turner R, Jickling G, Sharp F. Are underlying assumptions of current animal models of human stroke correct: from STAIRS to high hurdles? Transl Stroke Res. 2011;2(2):138-43.

41. Jickling GC, Sharp FR. Improving the translation of animal ischemic stroke studies to humans. Metab Brain Dis. 2014.

42. Tissue plasminogen activator for acute ischemic stroke. The National Institute of Neurological Disorders and Stroke rt-PA Stroke Study Group. N Engl J Med. 1995;333(24):1581-7.

43. Diener HC, Lees KR, Lyden P, Grotta J, Davalos A, Davis SM, et al. NXY-059 for the treatment of acute stroke: pooled analysis of the SAINT I and II Trials. Stroke. 2008;39(6):1751-8.

44. Lees KR, Zivin JA, Ashwood T, Davalos A, Davis SM, Diener HC, et al. NXY-059 for acute ischemic stroke. N Engl J Med. 2006;354(6):588-600.

45. Hacke W, Schellinger PD, Albers GW, Bornstein NM, Dahlof BL, Fulton R, et al. Transcranial laser therapy in acute stroke treatment: results of neurothera effectiveness and safety trial 3, a phase III clinical end point device trial. Stroke. 2014;45(11):3187-93.

46. Patel R, Ispoglou S, Apostolakis S. Desmoteplase as a potential treatment for cerebral ischaemia. Expert Opin Investig Drugs. 2014;23(6): 865-73.

47. Piechowski-Jozwiak B, Bogousslavsky J. The use of desmoteplase (bat saliva) in the treatment of ischaemia. Expert Opin Biol Ther. 2013;13(3):447-53.

48. von Kummer R, Albers GW, Mori E, Committees DS. The Desmoteplase in Acute Ischemic Stroke (DIAS) clinical trial program. Int J Stroke. 2012;7(7):589-96.

49. Paciaroni M, Medeiros E, Bogousslavsky J. Desmoteplase. Expert Opin Biol Ther. 2009;9(6):773-8.

50. Lyden P, Brott T, Tilley B, Welch KM, Mascha EJ, Levine S, et al. Improved reliability of the NIH Stroke Scale using video training. NINDS TPA Stroke Study Group. Stroke. 1994;25(11):2220-6.

51. Waud DR. On biological assays involving quantal responses. J Pharmacol Exp Ther. 1972;183(3):577-607.

52. NINDS. Tissue plasminogen activator for acute ischemic stroke. The National Institute of Neurological Disorders and Stroke rt-PA Stroke Study Group. N Engl J Med. 1995;333(24):1581-7.

53. Lapchak PA. A critical assessment of edaravone acute ischemic stroke efficacy trials: is edaravone an effective neuroprotective therapy? Expert Opin Pharmacother. 2010;11(10):1753-63.

54. Lapchak PA. Effect of internal carotid artery reperfusion in combination with Tenecteplase on clinical scores and hemorrhage in a rabbit embolic stroke model. Brain Res. 2009;1294:211-7.
55. Lapchak PA, Song D, Wei J, Zivin JA. Pharmacology of caffeinol in embolized rabbits: clinical rating scores and intracerebral hemorrhage incidence. Exp Neurol. 2004;188(2):286-91.

56. Albers GW, Bates VE, Clark WM, Bell R, Verro P, Hamilton SA. Intravenous tissue-type plasminogen activator for treatment of acute stroke: the Standard Treatment with Alteplase to Reverse Stroke (STARS) study. JAMA. 2000;283(9):1145-50.

57. Lapchak PA. Hemorrhagic transformation following ischemic stroke: significance, causes, and relationship to therapy and treatment. Curr Neurol Neurosci Rep. 2002;2(1):38-43.

58. Lapchak PA, Araujo DM. Advances in ischemic stroke treatment: neuroprotective and combination therapies. Expert Opin Emerg Drugs. 2007;12(1):97-112.

59. Lapchak PA, Araujo DM. Advances in hemorrhagic stroke therapy: conventional and novel approaches. Expert Opin Emerg Drugs. 2007;12(3):389-406.

60. Lyden PD, Madden KP, Clark WM, Sasse KC, Zivin JA. Incidence of cerebral hemorrhage after treatment with tissue plasminogen activator or streptokinase following embolic stroke in rabbits [corrected]. Stroke. 1990;21(11):1589-93.

61. Lyden PD, Zivin JA. Hemorrhagic transformation after cerebral ischemia: mechanisms and incidence. Cerebrovasc Brain Metab Rev. 1993;5(1):1-16.

62. Lyden PD, Zivin JA, Soll M, Sitzer M, Rothrock JF, Alksne J. Intracerebral hemorrhage after experimental embolic infarction. Anticoagulation. Arch Neurol. 1987;44(8):848-50.

63. Lapchak PA, Chapman DF, Zivin JA. Metalloproteinase inhibition reduces thrombolytic (tissue plasminogen activator)-induced hemorrhage after thromboembolic stroke. Stroke. 2000;31(12):3034- 40.

64. Fagan SC, Lapchak PA, Liebeskind DS, Ishrat T, Ergul A. Recommendations for preclinical research in hemorrhagic transformation. Transl Stroke Res. 2013;4(3):322-7.

65. Levine SR, Hill MD. NeuroThera Effectiveness and Safety Trial 3: how do we align corporate and scientific integrity to complete and report pharma-sponsored trials properly? Stroke. 2014;45(11):3175-7.

66. Lapchak PA, Zhang JH, Noble-Haeusslein LJ. RIGOR guidelines: escalating STAIR and STEPS for effective translational research. Transl Stroke Res. 2013;4(3):279-85.

67. Lapchak PA. Drug-like property profiling of novel neuroprotective compounds to treat acute ischemic stroke: guidelines to develop pleiotropic molecules. Transl Stroke Res. 2013;4(3):328-42.

68. Keep RF, Wang MM, Xiang J, Hua Y, Xi G. Full steam ahead with remote ischemic conditioning for stroke. Transl Stroke Res. 2014;5(5):535-7.

69. Liu X, Zhao S, Liu F, Kang J, Xiao A, Li F, et al. Remote ischemic postconditioning alleviates cerebral ischemic injury by attenuating endoplasmic reticulum stress-mediated apoptosis. Transl Stroke Res. 2014;5(6):692-700.

70. Bahjat FR, Gesuete R, Stenzel-Poore MP. Steps to translate preconditioning from basic research to the clinic. Transl Stroke Res. 2013;4(1):89-103.

71. Tajiri N, Dailey T, Metcalf C, Mosley YI, Lau T, Staples M, et al. In vivo animal stroke models: a rationale for rodent and non-human primate models. Transl Stroke Res. 2013;4(3):308-21.

72. Rosell A, Agin V, Rahman M, Morancho A, Ali C, Koistinaho J, et al. Distal occlusion of the middle cerebral artery in mice: are we ready to assess long-term functional outcome? Transl Stroke Res. 2013;4(3):297-307.

73. Kristian T, Hu B. Guidelines for using mouse global cerebral ischemia models. Transl Stroke Res. 2013;4(3):343-50.

74. Nobile CW, Palmateer JM, Kane J, Hurn PD, Schallert T, Adkins DL. Impaired limb reaction to displacement of center of gravity in rats with unilateral striatal ischemic injury. Transl Stroke Res. 2014;5(5):562-8.

75. Kunze A, Zierath D, Drogomiretskiy O, Becker K. Variation in behavioral deficits and patterns of recovery after stroke among different rat strains. Transl Stroke Res. 2014;5(5):569-76. 